\title{
Late morbidity of very low birthweight infants
}

\author{
M E IMOGEN MORGAN
}

\begin{abstract}
The use of hospitals in the first year after term was studied in a geographically based group of 111 very low birthweight infants in Liverpool. This was compared with that of 216 term infants without perinatal complications. Of the group with very low birth weight, $59(53 \%)$ were readmitted, with three deaths, compared with $21(10 \%)$ of the term infants. Of the admissions, 67 (40\%) related to sequels of neonatal illness or its management. The admissions were repeated and of long duration, resulting in a 16-fold increased load of inpatients, an eightfold increase in surgical procedures, and a twofold increase in attendance by outpatients at the local children's hospitals compared with the term group.

This population of infants after intensive care represented a high risk group with specific problems and requirements in infancy, even when problems were not apparent at discharge from the neonatal unit.
\end{abstract}

\section{Introduction}

Infants who require special or intensive care in the newborn period are recognised as being subject to several sequels of that care, both immediate and long term. These may derive mainly from the social circumstarices of the family, such as teenage mothers, single parent families, or the effects of separation in the postnatal period. Particularly in the very premature infants, however, they may derive from organic complications of neonatal disease or its treatment. This has late effects on growth, mental and physical development, lung disease, anaemia, immunity, and behaviour, and thus parenting. ${ }^{1}$ These complications may be sufficiently severe to require treatment in hospital or may be perceived to be so by parents or doctors.

The continuing morbidity and requirement for hospital services of very low biithweight infants since the era of neonatal intensive care have been studied predominantly in countries where provision of health services differs from that in the United Kingdom ${ }^{2-\text {; }}$ and in selected high risk neonatal groups.

\section{Patients and methods}

Between January 1980 and January 1983, 111 very low birthweight infants, whose home addresses at birth and at 1 year were within the city of Liverpool, were discharged from the regional neonatal intensive care unit at the Liverpool Maternity Hospital. This group did not include infants who were transported antenatally or postnatally to the regional unit. The records of these infants were sought at the two Liverpool children's hospitals in whose catchment area they lived, and ascertainment was increased by cross checking for changes of name and address in neonatal follow up records. Paediatric records were also sought for a control group of 216 term infants, whose names were obtained sequentially from the computerised alphabetical records of the Liverpcol community child health services, matched with the very low birthweight infants for place of birth, month and year of birth, and postal district.

Identified hospital records were analysed for duration and number of admissions, diagnoses, and outpatient attendances. When a neonatal history had been recorded details were noted and compared with the

Alder Hey Children's Hospital, Liverpool L12 2AP

$M$ E IMOGEN MORGAN, MB, MRCP, lecturer in child health factual record of the neonatal intensive care unit notes. Data were obtained for the first year from birth for the term infants and for the first year after discharge from the neonatal unit for the very low birthweight group.

\section{Results}

\section{CHARACTERISTICS OF THE VERY LOW BIRTHWEIGHT GROUP}

Of 111 infants studied, 25 weighed less than $1000 \mathrm{~g}$ at birth, of whom 18 required ventilation in the newborn period, and 86 weighed 1000 $1500 \mathrm{~g}$, of whom 42 were ventilated in the newborn period. Twenty two infants were ventilated for more than seven days, and seven had bronchopulmonary dysplasia. The mean birth weight of the group was $1170 \mathrm{~g}$ (range 630-1500) and mean gestation 30.1 weeks (range 2537). Thirty four infants were small for gestational age.

Fourteen infants had significant neurodevelopmental handicap by 1 year (tetraplegia (one), diplegia (five), hemiplegia (three), ataxic cerebral palsy (one), and global delay (four)), of whom 10 had sustained neonatal intraventricular haemorrhage.

\section{ADMISSIONS OF INPATIENTS}

Of 216 term infants, $21(9.7 \%)$ were admitted to hospital on 31 occasions in their first year (table I). The main reasons for admission were acute respiratory illnesses or gastrointestinal disturbances. Only six children $(2 \cdot 7 \%)$ were readmitted, the maximum number of admissions for any child being four. The median duration of admissions was 4.8 days. The maximum stay of any child in hospital over the first year was 48 days. Over the whole group the inpatient requirement totalled 0.8 days per child.

\begin{tabular}{lcc} 
TABLE I-Distribution of hospital admissions \\
\hline & $\begin{array}{c}\text { Very low } \\
\text { birthweight infants }\end{array}$ & Controls \\
\hline No of admissions & 136 & 31 \\
No (") () with: & $49(36)$ & \\
Complications of chronic disease & $52(38)$ & $12(39)$ \\
Acute respiratory problems & $8(6)$ & $9(29)$ \\
Gastric problems/failure to thrive & $15(12)$ & $6(19)$ \\
Surgical problems & $8(6)$ & \\
Social problems* & $3(2)$ & $4(13)$ \\
Cardiac problems & $1(1)$ & \\
Ophthalmic problems & &
\end{tabular}

In contrast, 59 of the $111(53 \%)$ very low birthweight infants were admitted to the children's hospitals after discharge from the neonatal unit (table I). The major reasons for admission were complications of chronic disorders arising from the neonatal period. The median duration of admission was nine days. Thirty one children $(28 \%)$ were readmitted often and for prolonged periods, so that the total number of admissions in this group was 136. The maximum stay of any child in hospital was 214 days. Over the whole group the inpatient requirement totalled 1454 days or $13 \cdot 1$ days per child.

The gestational age at birth of infants with later admissions was significantly lower than that of those who had none, suggesting a lower prevalence of late complications for infants small for gestational age (table II). Ventilation in the neonatal period was also associated with more admissions. Thirty six $(61 \%)$ of those admitted later had been ventilated compared with $24(46 \%)$ of those with no later admissions $\left(x^{2}=1.9, \mathrm{NS}\right)$. Ventilation in the neonatal period lasted longer (mean 11.7 days) in those infants admitted later to hospital than in those with no subsequent admissions (mean 4.8 days), which reflected their more stormy neonatal course. Data on maternal age and parity were available for 97 infants. There was no difference between the two groups. 
TABLE II-Admissions of very low birthweight infants

\begin{tabular}{|c|c|c|c|}
\hline & $\underset{(\mathrm{n}=59)}{\text { Admitted }}$ & $\begin{array}{l}\text { No admissions } \\
\quad(\mathrm{n}=52)\end{array}$ & Probability \\
\hline $\begin{array}{l}\text { Mean (SD) birth weight (g) } \\
\text { Mean (SD) gestation (weeks) }\end{array}$ & $\begin{array}{l}1160(220) \\
29 \cdot 4(2 \cdot 4)\end{array}$ & $\begin{array}{l}1180(220) \\
30 \cdot 7(2 \cdot 6)\end{array}$ & $\begin{array}{l}\text { NS* } \\
\mathrm{p}<0.02 \dagger\end{array}$ \\
\hline
\end{tabular}

* Mann-Whitney U test $=0 \cdot 22$.

† Mann-Whitney U iest $=2.06$.

\section{SURGICAL PROBLEMS}

Two infants required pyloroplasty and one repeated anal dilatations, and two underwent examinations of the eyes under anaesthesia. Among the very low birthweight infants $12(10.8 \%)$ required inguinal hernia repairs in the first year at an average age of 4 months after birth. In one further child a repair was done at 18 months. Of these infants, seven had possible predisposing factors (hydrocephalus with shunt (two), bronchopulmonary dysplasia (three), and ventilation for five and 10 days (two)).

Six infants required ventriculoperitoneal shunts for posthaemorrhagic hydrocephalus. In all but one these were inserted before discharge from the neonatal unit. Three infants required late ligation of persistent ductus arteriosus. One required an examination of the eyes under general anaesthesia.

\section{UPPER RESPIRATORY PROBLEMS}

Three infants required tracheostomy in their first year, one before discharge after prolonged intubation. The two other infants developed acute stridor at 6 and 7 months after viral croup in one case and intubation for surgery for hernia in the other. Croup occurred often in respiratory illnesses in the group, and five infants had diagnostic laryngoscopies between 3 and 18 months old, all of which were consistent with subglottic stenosis. Tracheal dilatation was attempted in the two infants noted previously but was unsuccessful, and tracheostomy followed.

\section{RESPIRATORY ILLNESSES}

Eleven term infants $(5 \cdot 1 \%)$ were admitted to hospital primarily because of respiratory illness. One was admitted twice. Of these, seven were assessed by the admitting medical staff as having infections of the lower respiratory tract. Thirty seven (33\%) very low birthweight infants were admitted to hospital with respiratory illness, a total of 62 admissions. Twenty five had been ventilated in the newborn period; three had whooping cough; and the rest had illnesses characterised by wheeze and auscultatory changes and sometimes by development of opacities on $x$ ray examinations of the chest. These were diagnosed by medical staff as croup, bronchiolitis, wheezy bronchitis, and pneumonia, but there was considerable clinical overlap, and bacteriological and virological investigations were seldom helpful, although antibiotic treatment was usually given.

Six of the seven infants with neonatal bronchopulmonary dysplasia were admitted later in this category.

\section{ADMISSIONS FOR SOCIAL REASONS}

The capacity of the family to cope with any problem may be a more important factor in the decision to admit than is the intrinsic severity of the disorder. While social reasons or failure to thrive were mentioned by the admitting doctor in five of the admissions of term babies, these were mentioned in only 17 of the admissions of very low birthweight infants, a lower proportion. Only three of these infants had major neurological problems. Overt child abuse was not noted in any child.

\section{DEATHS}

None of the control infants died, but three $(2 \cdot 7 \%)$ of the very low birthweight infants did. The first, birth weight $750 \mathrm{~g}$, had severe bronchopulmonary dysplasia, pulmonary hypertension, and heart failure and died after a chest infection at home aged 7 months. The second, birthweight $1100 \mathrm{~g}$, died in hospital of fulminant pneumoniag aged 5 months. The third, birthweight $1400 \mathrm{~g}$, died suddenly at home aged 6 months; no cause of death was evident at necropsy.

\section{ATTENDANCE BY OUTPATIENTS}

Considerable inconvenience and expense is incurred by parent bringing their small infants to hospital. Thirty five control infants $(16 \%)$ made 108 visits to hospital as outpatients over their first year mainly for orthopaedic checks. Forty $(36 \%)$ very low birthweight. infants made 120 visits as outpatients for various problems, excludin $\overrightarrow{5}$ appointments for neonatal follow up and visits to paramedical agencies such as physiotherapy (table III).

TABLE III-Outpatient attendances

\begin{tabular}{lcc}
\hline & $\begin{array}{c}\text { Very low } \\
\text { birthweight infants } \\
(\mathbf{n}=40)^{*}\end{array}$ & $\begin{array}{c}\text { Controls } \\
(\mathrm{n}=35) \dagger\end{array}$ \\
\hline No (\%) with: & $35(29)$ & $1(1)$ \\
Developmental problems & $20(17)$ & $5(5)$ \\
Respiratory problems & $18(15)$ & $16(15)$ \\
Feeding and growth problems & $10(9)$ & $61(56)$ \\
Orthopaedic problems & $10(9)$ & $1(1)$ \\
Cardiac problems & $5(4)$ & $8(7)$ \\
Ophthalmic problems & $22(17)$ & $14(13)$ \\
Minor surgical problems & & $2(2)$ \\
Dermatological problems & & \\
\hline
\end{tabular}

$*$ Total $=111$.
+ Total $=216$.

\section{CONTINUITY}

The very low birthweight infants admitted to hospital were under the care of several medical and surgical consultants. The neonatal notes were usually unavailable at the time of emergency admission, thoughro they could be requested thereafter.

In the initial admitting note factual errors in the neonatal history obtained from accompanying parents occurred in seven infants. Details of the neonatal course were omitted in three infants presenting with respiratory illnesses, who had earlier been ventilated. In one childō with inguinal hernias surgery was delayed because of the appearance of the $x$ ray film of the chest, though he had had prolonged ventilation and bronchopulmonary dysplasia, which were not recorded. The details of neonatal ventilation in the histories of two infants were inaccurate, and a history of necrotising enterocolitis was not recorded in one child presenting for hernia repair.

\section{Discussion}

The morbidity of the very low birthweight infant extends beyond the neonatal period. The disadvantageous socioeconomico factors associated with preterm delivery lead to a higher risk of 3 later illness and return to hospital. ${ }^{8-10}$ Additionally, respiratoryo distress syndrome results in structural and functional changes in $N$ the lung, which are detectable throughout childhood and may lead to altered bronchial reactivity to allergens or pathogens, ${ }^{11-12}$ while hernias may result from earlier excessive intra-abdominal pressures.

This group of infants had a higher rate of admissions to hospital in their first year than any previously recorded series, although the rate and duration of admissions for term infants were ino keeping with those in other series. ${ }^{14}{ }^{15}$ Factors affecting ad- $\Phi$ missions include month of birth, with an increase in early? admissions in the children born in winter, ${ }^{16}$ disadvantaged home backgrounds, and lack of domiciliary support; $20 \%$ of ad- $\frac{O}{\mathbb{P}}$ missions in one series in Nottingham were primarily social. ${ }^{\circ}$ The factors were confirmed by Cullinan in London. ${ }^{8}$ Such dis- $\stackrel{\mathbb{Q}}{\varrho}$ advantages patently affect the very low birthweight group too $\bar{O}$ Respiratory illnesses result from increased exposure to cigaretteo smoke, and overcrowding leads to increased viral exposure. Sudden unexplained death in infancy and death due to chronic lung disease and infections were increased up to 10-fold in infants who had been admitted to a neonatal intensive care unit, even 
in those infants who were discharged apparently normal and free of sequelae. ${ }^{1 / 1 \times}$

These factors added together make it extremely important that an accurate neonatal history is available when such infants come to hospital. The memory of the accompanying parent may be unreliable. If the infant has originally been transferred from local facilities to a neonatal regional centre the paediatric medical and surgical staff may not always have instant access to neonatal records. Changes of name may confuse the search for previous records $\left(10^{\circ}\right.$ of this group had a different surname by the end of one year), and many admissions result from self referral so that the general practitioner's information is not available. Each area requires its own contingency plans for obtaining data in these situations, certainly within 24 hours of admission if not immediately.

This population of infants provides "new" problems for anaesthetists, paediatricians, and paediatric surgeons in addition to their better known and multiple neurodevelopmental difficulties. They also require proportionately more (here 16.4 times more) facilities for inpatients than term infants.

Even those infants who had apparently uncomplicated neonatal courses appeared to have considerably raised incidences of morbidity and even mortality throughout infancy, suggesting adverse consequences or correlates of their low birth weight itself. As being in hospital itself can lead to deleterious consequences in development at 2 years, ${ }^{19}$ and in later behaviour and learning even in adolescence, ${ }^{20}$ the importance of these medical and surgical problems should not be underestimated.

I thank Dr E J Bushby, Dr R W I Cooke, and the consultants o Alder Hey Children's Hospital and the Royal Liverpool Children's Hospital for allowing me access to their patients' records.

\section{References}

1 Hurt H. Continuing care of the high-risk infant. Clin Perinatol 1984;11:3-17 Hurt H. Continuing care of the high-risk infant. Clin Perinatol 1984;11:3-17
McCormick MC, Shapiro S, Stanfield BH. Rehospitalization in the first year of life for high-risk survivors. Pediatrics 1980;66:991-9.

Hack M, DeMonterice D, Merkatz IR, Jones P, Fanaroff AA. Rehospitalization of the very low birth weight infant: a continuum of perinatal and environmental morbidity. Am 7 Dis Child $1981 ; 135 \cdot 263-6$

4 Markestad T, Fitzhardinge PM. Growth and development in children recovering from broncho-pulmonary dysplasia. F Pediatr 1981;98:597-602.

Littman B, Parmelee AH. Medical correlates of infant development. Pediatric $1978 ; 61: 470-4$

6 Pape KE, Buncic RJ, Ashby S, Fitzhardinge PM. The status at two years of low birth weight infants born in 1974 with birth weights of less than 1001 grams. f Pediatr 1978;92:253-60

7 Fitzhardinge PM, Pape K, Arstikaitis M, ct al. Mechanical ventilation of infants of less than 1501 grams birth weight: health, growth and neurologic sequelac

Cullinan TR, Saunders DI. Prediction of infant hospital admission risk. Arch Dis

ynne J, Hull D. Why are children admitted to hospital? Br Med f 1977; ii:

10 Taylor B, Wadsworth J, Butle NR. Teenage mothering, admission to hospital, and accidents during the first five years. Arch Dis Child 1983;58:6-11.

11 Outerbridge EW, Nogrady MB, Beaudry PH, Stern L. Idiopathic respiratory distress syndrome. Recurrent respiratory illness in survivors. Am $\mathcal{F}$ Dis Child 1972;123:99-104.

12 Lindroth $M$, Johnson B, Svenningsen NW, Mortensson WW. Pulmonary mechanics, chest $\mathrm{X}$ ray, and lung disease after mechanical veintilation in low birth weight infants. Acta Paediatr Scand 1980;69:761-70

13 Stocks J, Godfrey S. Role of artificial ventilation, oxygen, and CPAP in the pathogenesis of lung damage in neonates: assessment by serial measurements of lung function. Pediatrics 1976;57:352-62.

14 Chamberlain RN, Simpson RN. The prevalence of illness in childhood. London:

15 Carmichael A, W'illiams HE. Patterns of illness in an infant population in a poor socio-economic status multi-ethnic municipality. Aust Paediatr $71983 ; 19$ :

16 Lloyd B, Pursall E, Emery JL. Hospital morbidity pattern in children under 1 year of age born in Sheffield 1975-6. Arch Dis Child 1981;56:36-9.

17 Kulkarni P, Hall RT, Rhodes PG, Sheehan MB. Postneonatal infant mortality in infants admitted to a neonatal intensive care unit. Pediatrics 1978;62:178-83. Sells CJ, Neff TE, Bennett I:C, Robinson NM. Mortality in infants discharged from a neonatal intensive care unit. Am 7 Dis Child $1983 ; 137: 44-7$.

9 Littman B, Parmelee AH. Medical correlates of infant development. Pediatric $1978 ; 61: 470-4$

20 Douglas JWP. Early hospital admissions and later disturbances of behaviour and learning. Dev Med Child Neurol 1975;17:456-80.

(Accopted 4 fune 1985)

\title{
Treatment of ingrowing toenails with liquid nitrogen spray cryotherapy
}

\author{
T S SONNEX, R P R DAWBER
}

\begin{abstract}
Ingrowing toenails are a common debilitating condition and often require surgical intervention. In 44 patients liquid nitrogen spray cryotherapy produced a rate of success comparable with that of other nail sparing techniques but had the advantage of being a quick, simple, and cheap outpatient procedure that could be carried out with limited facilities and without anaesthesia.
\end{abstract}

\section{Introduction}

Ingrowing toenails are common, particularly in young adults, and usually result in a prolonged period of discomfort or pain

Department of Dermatology, Slade Hospital, Oxford OX3 7JH

T S SONNEX, MB, MRCP, registrar

R P R DAWBER, MB, FRCP, consultant

Correspondence to: Dr T S Sonnex, St John's Hospital for Diseases of the Skin, London WC2H 7BJ. that is sufficient to interfere with working and social activities. Several aetiological factors have been implicated, including ill fitting footwear, incorrect cutting of nails, poor foot hygiene, hyperhidrosis, malalignment of the matrix, abnormally long toes, congenital excessive convexity of the nails, and prominence of the nail folds. Although a fundamental aim of management must be to correct these predisposing factors, further measures are usually required at the time of presentation. Antiseptic soaks, systemic antibiotics, regular pushing back of the nail fold, and packing of the lateral groove with cotton wool are usually tried, but a response, if it occurs, takes time and considerable effort by the patient. As recurrences are common an operation is the next inevitable step.

Nail ablation consistently produces the highest cure rates but is relatively time consuming and requires a high degree of skill by the operator. Patients are also not keen to lose part of the nail permanently unless there is no alternative. Any feasible alternative should be a simple, quick, cheap outpatient procedure that can be carried out with limited facilities by relatively inexperienced operators and that produces rapid relief of pain associated with an acceptable cure rate.

As cryotherapy fits most of these criteria we considered its use in the treatment of ingrowing toenails. Four of the main features of ingrowing toenails are pain, secondary infection, excessive 